\title{
Ensinar por meio da Pedagogia por Projetos: reflexões acerca da prática de uma professora iniciante
}

\author{
Teaching through Project Pedagogy: reflections on the practice of a beginning \\ teacher
}

\author{
Daiane Luzia de Matos Bueno' \\ Fabiana Rosa Vilela de \\ Oliveira Guilherme ${ }^{2}$
}

\section{RESUMO}

O artigo apresenta a análise de uma professora iniciante de carreira sobre a própria prática ao adequar suas ações pedagógicas à perspectiva da concepção de ensino pela Pedagogia por Projetos de Josette Jolibert no decorrer de uma investigação qualitativa na modalidade Pesquisa-ação. Discorre tanto sobre diálogos e estudos ocorridos junto aos pares de um Grupo de Estudos e Pesquisa em Alfabetização quanto reflexões individuais sobre conceitos advindos de uma concepção interacionista do ensino e da aprendizagem aplicada à própria prática docente em uma turma de $2^{\circ}$ ano do Ensino Fundamental, no ano de 2018. Mediante embasamento dos referenciais teóricos de Micotti, Schön, Tardif, Ortiz, Jolibert, para atingir o objetivo proposto, a professora pesquisadora levantou seus registros das ações com as crianças em aulas, o que resultou em uma modalidade de ensino interativa em construção, porém, com ação-reflexão-ação entre prática e teoria.

Palavras-chave: Pedagogia por projetos. Trabalho docente. Professor reflexivo.

\begin{abstract}
The article presents the analysis of a beginning career teacher on her own practice by adapting her pedagogical actions to the perspective of the concept of teaching by Pedagogy by Projects by Josette Jolibert during a qualitative investigation in the Action Research modality. It discusses both dialogues and studies that took place with the peers of a Study and Research Group in Literacy, as well as individual reflections on concepts arising from an interactionist conception of teaching and learning applied to her teaching practice in a class of 2nd year of Elementary Education, in 2018. The methodological approach is qualitative, of action research, based on the theoretical frameworks of Micotti, Schön, Tardif, Ortiz, Jolibert. To achieve the proposed objective, the researcher teacher collected her records of actions with children in classes, which resulted in an

\footnotetext{
${ }^{1}$ Professora da Educação Básica. Mestranda no Programa de Pós-Graduação em Educação da Universidade Estadual Paulista “Júlio de Mesquita Filho" - UNESP/IB - Campus de Rio Claro, daianematos.30@gmail.com

${ }^{2}$ Diretora de Escola Substituta. Mestre em Educação. Doutoranda no Programa de Pós-Graduação em Educação da Universidade Estadual Paulista “Júlio de Mesquita Filho" - UNESP/IB - Campus de Rio Claro, fabianavguilherme@gmail.com
} 


\section{-Revista de Iniciação à Docência, v.6, n.2, 2021- \\ Publicação: dezembro, 2021 - ISSN 2525-4332}

interactive teaching modality under construction, however, with action-reflection-action between practice and theory.

Keywords: Pedagogy by projects. Teaching work. Reflective teacher.

\section{Introdução}

Este artigo busca contribuir com os estudos sobre alfabetização mediante análise de práticas interdisciplinares, trabalho docente em início de carreira e formação de professores reflexivos na contemporaneidade. Enfatiza o ensino por meio de uma pedagogia ativa de projetos que segue as inovações conceituais advindas das propostas educacionais iniciadas na década de 80 , no país, devido às políticas e legislações vigentes nos textos da Carta Constitucional de 1988 (BRASIL, 1988), na Lei de Diretrizes e Bases da Educação Nacional - LDB 9394/96 (BRASIL, 1996) e, atualmente, na Base Nacional Comum Curricular - BNCC - (BRASIL, 2017), documentos manifestos de citações ao desenvolvimento humano desde a infância e aos direitos da criança, no que tange à educação.

A tentativa em adequar os preceitos regidos nessas legislações e documento curricular focaliza os olhares para a escola, principalmente, para a atuação dos professores em aulas durante a alfabetização, colocando em xeque a modalidade de tal atuação e a formação profissional dos docentes. Desse modo, a alfabetização tem sido alvo de intensas pesquisas que buscam compreender os processos complexos que a envolvem. Essa complexidade permite que a alfabetização seja estudada por diferentes ângulos, através de métodos diversificados que abrangem diferentes áreas do conhecimento (MICOTTI, 2003, 2017).

Segundo Micotti (2017, p.7), as justificativas para que a alfabetização seja intensamente pesquisada são as de que "as dificuldades referentes à alfabetização comprometem uma das principais funções da escola" que é a de socializar os saberes produzidos historicamente pela humanidade, nas questões filosóficas, científicas, sociais e práticas que a envolvem. Dentre as diversas funções da escola, alfabetizar a criança é primordial e está na base dos deveres educacionais, por isso, reflete diretamente sobre o trabalho docente e sua formação.

Nesse contexto, estudos atuais sobre formação e trabalho docente estão amplamente voltados para a versatilidade de um profissional reflexivo, questionador de suas ações e resultados mediados por referenciais teóricos que embasam suas práticas (SCHÖN, 1992; TARDIF, 2010, 2020; NÓVOA, 2017; SMYTH, 1992; ORTIZ, 2003). Esses focalizam uma educação prática-reflexiva. Schön (1992, p.25) configura a "epistemologia da prática" no entrelaçamento da dicotomia entre teoria e prática no local da profissão (nas instituições) suscitando o movimento de reflexão na e sobre a ação durante o trabalho docente e formação profissional. 
Essas pesquisas que evidenciam a importância da formação de professores reflexivos com ênfase na relação das ações com teorias preconizam a busca de propostas pedagógicas que envolvam os estudantes em ações autônomas de mais interatividade com o objeto de estudo. Sendo assim, surge a relevância do presente artigo que dialoga nessa perspectiva de análise da prática de uma professora reflexiva e pesquisadora, inserida na congruência de ideias com integrantes de um grupo de estudos e pesquisas em alfabetização, mediante a busca pela superação das práticas tradicionais de ensino que pouco consideram a ação do sujeito aprendiz na construção de seu conhecimento.

Assim, os seguintes questionamentos norteiam essa investigação: quais as descobertas e anseios vivenciados pela professora durante as adequações dessa modalidade interativa de ensino em sua prática pedagógica? Quais as contribuições da Pedagogia por Projetos para a formação profissional de uma professora iniciante de carreira quando esse processo caminha numa ação e reflexão contínua com sua prática?

$\mathrm{Na}$ busca pelas respostas a essas questões, apresentamos o estudo realizado no decorrer do ano de 2018, durante as aulas de matemática. Os dados foram organizados a fim de atender ao objetivo geral de discorrer e analisar acerca da prática de uma professora iniciante ao buscar adequar a perspectiva da concepção de ensino pela Pedagogia por Projetos de Josette Jolibert a suas ações pedagógicas e as contribuições deste processo para sua formação profissional.

Essa pesquisa levanta o pressuposto de que a aprendizagem da profissão docente, durante o processo da ação prática, possibilita assimilações mais eficazes sobre sua própria formação e saberes no exercício da profissão. Este professor, que reflete seus fazeres e saberes cotidianos, pode compreender o processo de aprendizagem do aluno de modo mais amplo, mediante práticas emancipatórias.

Para isso, a escolha de uma Pedagogia Ativa - como a Pedagogia por Projetos, de Josette Jolibert et al. (1994a) - coaduna com a concepção de que, nesse processo de pesquisar e fazer, o professor constrói seu conhecimento profissional enquanto exercita o trabalho e se relaciona com estudos científicos, prosperando em conhecimentos teóricos e práticos.

Desse modo, nesse artigo discorremos sobre o contato inicial com a Pedagogia por Projetos, descrevemos as atividades realizadas junto aos discentes e as reflexões que resultaram no princípio da (trans)formação da prática pedagógica.

\section{A Pedagogia por Projetos como Modalidade de Formação Continuada do Professor Reflexivo}

Dentre as diversas Pedagogias Ativas optamos pela Pedagogia por Projetos da francesa Josette Jolibert porque essa intensifica a modificação das práticas pedagógicas, provoca reflexão sobre as ações em aulas, a atividade discente é valorizada, os 


\section{-Revista de Iniciação à Docência, v.6, n.2, 2021- \\ Publicação: dezembro, 2021 - ISSN 2525-4332}

professores e alunos mantêm diálogo constante e são propiciadas diferentes possibilidades aos estudantes para que a aprendizagem aconteça: por meio de hipóteses, ações, observações, análises e avaliações durante as atividades escolares e para além dela.

Cabe ressaltar que a Pedagogia por Projetos propicia uma transformação do ato educativo na busca pela superação das dificuldades e fracassos que permeiam a aprendizagem e o ensino de cada criança e da turma. Concede uma vida cooperativa com ações democráticas e participativas dos sujeitos na escola. O professor torna-se reflexivo de sua prática, como salienta Schön (1992), com reflexão na ação, reflexão sobre a ação e reflexão sobre a reflexão na ação, focalizando a própria formação profissional de modo contínuo.

As pesquisas sobre o professor reflexivo crescem com o movimento mundial de reformas educacionais entre as décadas de 80 e 90 com autores como Schön, (1992; 2000), Nóvoa (1992), Smith (1992) e, após os anos 2000, Ortiz (2003), entre outros, que levantaram críticas ao modelo da racionalidade técnica do programa inicial de universitarização da formação inicial da profissão docente, que apesar de ser um marco para a profissão, privilegia os primeiros anos da faculdade aos conhecimentos teóricos e deixa a aplicação prática apenas ao último ano do curso, reservando as adequações práticas ao âmbito de formações continuadas.

Santos (2015) adverte, no entanto, que ainda enfrentamos essa problemática nos cursos de formação inicial, o que nos conduz a refletir que os currículos das licenciaturas, de modo geral, permanecem pautados na concepção linear e racionalista em que a prática é compreendida como produto de uma teoria ou da aplicação de resultados das pesquisas científicas. Os dados desse estudo mostram que os cursos ainda separam os polos teoria e prática, porém, deveriam buscar meios de fundi-los e de se complementarem pela atividade do sujeito, no seu processo de trabalho, entendido no contexto da experiência humana e social.

Ainda, segundo a autora "podemos refletir que teoria e prática encontram-se entrelaçadas nos diferentes saberes que compõem o conhecimento do professor, o que constitui o conhecimento profissional docente" (SANTOS 2015, p. 18127).

Para a aquisição desse conhecimento profissional do professor, além dos cursos de formação, Nóvoa (2017, p.1121) afirma que é preciso “disposição pessoal” para aprender a profissão docente. Para que isso ocorra, Ghedin (2010, apud LIMA; BRAGA 2016, p. 74) sinaliza que, ao eleger a reflexão como caminho, esta requer de cada pessoa um ato de vontade e ação de coragem em busca de possibilidades e mudança. Mesmo com contradições e limites, que impedem ou dificultam a reflexão, "é preciso um impulso de superação para descobrir as portas abertas em direções que ainda não havíamos percebido. Assim, o conhecimento é uma possibilidade de reaver a dignidade do ser humano inserto no contexto social". 


\section{-Revista de Iniciação à Docência, v.6, n.2, 2021- \\ Publicação: dezembro, 2021 - ISSN 2525-4332}

Esses autores ressaltam que, para Freire (1996), o trabalho educacional precisa partir de fatores da realidade, no intuito de possibilitar diálogo permanente com a reflexão num processo de formulação do conhecimento, com suporte na relação teoriaprática. Na busca da análise da prática e da leitura de mundo, estão imbricadas as posturas dos professores, que procuram desenvolver a "prática de pensar a prática", cabendo-lhes empreender o exercício de uma competência geral e saberes específicos, ligados à sua atividade docente (FREIRE, 1996, p. 70 apud LIMA; BRAGA 2016, p. 78).

Existem algumas formas que determinados autores encontraram para relacionar a teoria com a prática durante o exercício profissional. Pimenta (2005) e Jolibert et al. (2007) sugerem a pesquisa colaborativa e a pesquisa-ação como modalidades significativas de estudos que corroboram com a concepção de um professor reflexivo e prático, porque propiciam planejamento, ação, reflexão, replanejamento e nova ação, num ciclo embasado de aspectos teóricos.

Smyth (1992) e Ortiz (2003) valorizam o registro reflexivo do professor quando propõe que este descreva, informe, confronte e reconstrua os modos de fazer e refletir as ações da prática com questões, entre outras, que ajudam o professor pensar por que, o que e como faz. Nesse sentido, apresentaremos a seguir os caminhos metodológicos da pesquisa, as ações práticas e reflexões desenvolvidas, e a relação estabelecida com conceitos teóricos mediante a Pedagogia por Projetos.

\section{Aspectos Metodológicos da Pesquisa}

Esse trabalho de cunho qualitativo, realizado na perspectiva da pesquisa-ação, que segundo Tripp (2005, p.443-446), é uma forma de investigação-ação, a qual define

sucintamente como "toda tentativa continuada, sistemática e empiricamente fundamentada de aprimorar a prática" e que segue um ciclo reflexivo para aprimorar as ações profissionais "pela oscilação sistemática entre agir no campo da prática e investigar a respeito dela".

Como metodologia, buscou-se seguir o ciclo de investigação que rege a pesquisaação: planejar as ações com a turma e consultar os conceitos teóricos sobre ensino e aprendizagem; implementar o que foi planejado a fim de melhorar a prática e ajustar o quê, quando e como fazer; descrever e analisar os efeitos das ações nas aulas e as reflexões anotadas em caderno, bem como em gravações dos diálogos entre os sujeitos; conversas com os pares professores; avaliar os resultados da ação sob o olhar teórico e recomeçar o ciclo para a mudança e aperfeiçoamento da práxis, aprendendo no decorrer do processo.

O trabalho analisado neste artigo foi desenvolvido em 2018, com uma turma de $2^{\circ}$ ano do Ensino Fundamental, composta por 24 crianças em idades entre 7 e 8 anos. Por meio da Pedagogia por Projetos, desenvolvemos o projeto intitulado pelas crianças 
“Alimentação Saudável”. Este teve a duração de três meses, de setembro a dezembro do mesmo ano.

Como instrumentos de coleta de dados recorremos ao nosso acervo pessoal, composto por caderno de anotações, fotografias e gravações em áudio dos diálogos ocorridos durante o processo de ensino e aprendizagem nas aulas, a fim de compreender os aspectos que suscitam autorreflexões sobre a ação e também os registros das análises realizadas coletivamente em nossa parceria de Grupo de Estudos.

É importante esclarecer que houve constantes retornos ao referencial teórico, realizados no processo do exercício das práticas pedagógicas e nos (re)planejamentos das aulas, já que muitas dúvidas surgiram no exercício de reflexão das ações.

\section{O trabalho docente com o projeto "alimentação saudável" e o processo de ensino reflexivo}

O primeiro contato com a Pedagogia por Projetos foi por intermédio de uma Universidade Pública, mediante localização do Grupo de Estudos em Alfabetização Raios de Sol da Universidade Estadual Paulista UNESP/Rio Claro pelo Facebook, percebendo que uma das integrantes era colega de trabalho. Após contato com ela, comecei ${ }^{3}$ a frequentar o Grupo e a Profa. Coordenadora e demais integrantes apoiaram minha formação nessa perspectiva, porque estudavam e aplicavam a Pedagogia por Projetos de Josette Jolibert em suas práticas didáticas.

Não queria trabalhar de modo tradicional, mas não conhecia outro caminho! Com o tempo, estreitei um diálogo frequente com uma das parceiras que abriu novos conhecimentos para o desenvolvimento de meu trabalho. Cabe destacar que ingressei no magistério no ano de 2018, aprovada em concurso público, com 35 anos, no Ensino Municipal do Interior Paulista.

Assumi essa turma no mês de junho, na disciplina de Matemática, pois a turma estava sem professor para essa área de conhecimento. No entanto, apesar de ministrar aulas na disciplina de Matemática, senti necessidade de colaborar com a alfabetização da língua, pois as crianças encontravam-se nessa fase da aprendizagem e a falta de leitura por parte dos estudantes comprometia a compreensão de algumas das atividades propostas, principalmente, quanto aos enunciados dos problemas matemáticos.

O grupo de crianças era bastante heterogêneo e possuía três casos de inclusão, entre os quais um com diagnóstico de Deficiência Intelectual e dois em processo de avaliação clínica, acompanhados pelo Atendimento Educacional Especializado, oferecido pela Unidade Educacional.

As disciplinas, nessa escola, funcionavam em período integral, organizadas por

\footnotetext{
${ }^{3} \mathrm{~A}$ partir desse momento utilizaremos a escrita em primeira pessoa do singular, pois trata-se de reflexões de uma das pesquisadoras e participante deste artigo.
} 


\section{-Revista de Iniciação à Docência, v.6, n.2, 2021- \\ Publicação: dezembro, 2021 - ISSN 2525-4332}

áreas, e cada professor era responsável por duas turmas, uma vez que assumem apenas a disciplina de Língua Portuguesa que é trabalhada no período da manhã ou Matemática, à tarde. Além disso, os conceitos de Natureza e Sociedade (que englobam Ciências, História e Geografia) eram trabalhados em ambos períodos, e ainda oferecidas oficinas de esportes, cultura e robótica, distribuídas entre essas aulas.

A maioria das crianças da turma era moradora de bairros próximos à escola, localizada em região periférica, e apresentava níveis bastante distintos de saberes. Apenas cinco estudantes apresentavam desempenho correspondente ao previsto para o $2^{\circ}$ ano. O perfil da turma era o de agitada e participativa, mas a participação nem sempre se fazia coerente com a aula, frequentes conflitos estabeleciam-se como agressões verbais e físicas.

As crianças disputavam a minha atenção enquanto professora, dificultando as atuações nas aulas. Conclui que, talvez fosse porque ficaram muito tempo sem professora de matemática, desde o início do ano, sendo deslocados para outras turmas em pequenos grupos. O desenvolvimento da aprendizagem por parte dos alunos estava bastante prejudicado, comprometendo também a organização do trabalho, rotina e disciplina dos educandos.

Quando iniciei um questionamento com as crianças sobre o que conheciam e sentiam a respeito da matemática, a princípio, os alunos demonstraram certa aversão à matéria. Alguns diziam: "matemática é difícil”, "eu não gosto de matemática”, "não quero estudar matemática". Isso precisava ser, gradativamente, reconstruído. O desafio que enfrentava como professora recém-formada em meu primeiro ano de trabalho levoume em busca de propostas que subsidiassem a prática, de modo que os alunos fossem protagonistas no processo de ensino, desenvolvendo condutas participativas e democráticas, superando as suas dificuldades e progredindo nos conteúdos previstos para o ano de escolaridade.

\section{Apresentação dos Resultados}

Os resultados mostram os momentos em que eu, na posição de professora, expresso minhas reflexões durante o processo prático pedagógico, ou para além dele, ao fazer registros dos momentos em que foi necessário retornar ao referencial teórico e fazer reflexões.

Nos primeiros contatos com a Pedagogia por Projetos, já estava lecionando para a turma há dois meses, então, foi necessária uma adequação das assimilações processuais dos conceitos da proposta para minhas práticas. Quando tomei contato com os primeiros textos dessa proposta, percebi que essa concepção se adequava à minha visão de educação, e era exatamente nos moldes dessa pedagogia que pretendia conduzir as aulas, o que me propiciou incorporar com facilidade os pressupostos da Pedagogia por 
Projetos no cotidiano docente.

Em dado momento, ao tomar contato com a obra de Jolibert et al. (1994a, p.20) verifiquei que a autora descreve a Pedagogia por Projetos como uma concepção que valoriza o protagonismo discente por meio de atividades oriundas de seus interesses, desenvolvidas em contextos significativos e reais, bem como em ambientes colaborativos, levando em consideração o que a autora pontua, "a atividade do sujeito aprendiz é determinante na construção de seu saber operatório". Pude refletir que valeria a pena iniciar a incursão no desafio de desprender-me do controle das aulas, permitindo que as crianças agissem em um ambiente de colaboração.

Comecei a desenvolver conversas sobre estudos com uma das integrantes do grupo para entender melhor o processo de ensino e aprendizagem que rege a Pedagogia por Projetos e, ao final do trabalho com as crianças, culminou neste artigo a fim de contribuirmos com estudos sobre os diálogos e conhecimentos adquiridos no processo prático-teórico.

Verificamos as propostas curriculares para Educação Básica contidas nos documentos oficiais do município (LIMEIRA, 2016) e as articulações para que os alunos estivessem no centro de seu processo de ensino e aprendizagem, visto que, conforme Jolibert et al. (1994a, p. 12) "é na medida em que se vive em um meio sobre o qual é possível agir, no qual é possível com os outros, discutir, decidir, realizar, avaliar [...] que são criadas as condições mais favoráveis ao aprendizado". Registrei essa citação em meu caderno de notas, pois, passei a valorizar as anotações das aprendizagens durante o processo. Os registros de minhas ações e saberes, assim como das falas e descobertas das crianças, tornaram-se cotidianos em minha prática. Com o tempo percebi sua importância para o planejamento das próximas aulas e também para conhecer melhor os estudantes!

A preocupação inicial, ao levar para sala de aula essa pedagogia, era a de relacionar os meus objetivos de professora com a proposta curricular da Rede Municipal de Ensino. Com o tempo, através das leituras e dos questionamentos, percebi que era preciso enfatizar um trabalho para a autonomia das crianças, colocar o aluno em cena durante as etapas do ensino, pois, para Jolibert et al. (1994a), na configuração de escola, pouco se pensa em para quem ela é de fato destinada. Micotti (2009, p. 38) assinala que "na perspectiva dos projetos, as aulas deixam de ser um mundo de faz de conta para constituírem-se em encontro de subjetividades", propiciando um trabalho pedagógico coletivo que leva os estudantes a refletirem entre eles a realidade na qual estão inseridos; assim as aulas não são mais "cumprimento de obrigações” desprovidas de sentido.

Sobre o planejamento e consulta da teoria, pensava em: como começar o trabalho com projetos? Ao conversar com minha parceira de estudos e integrante do Grupo de Estudos, ela me responde: - "Inicialmente questione os estudantes sobre o que desejam aprender, como em uma tempestade de ideias. No capítulo 2 do Livro Formando Crianças 


\section{-Revista de Iniciação à Docência, v.6, n.2, 2021- \\ Publicação: dezembro, 2021 - ISSN 2525-4332}

Leitoras, de Jolibert et al., você encontra sobre a Vida Cooperativa e Pedagogia por Projetos".

Após ler as páginas sugeridas, concluí que as discussões da autora sobre as relações de poder e construção de sentido nas interações com a leitura e a escrita nas aulas devem permitir às crianças que construam o sentido de sua atividade de aluno, sendo o ponto de partida o questionamento "do quê", "como", "para quê" e "por quê" aprender determinados conteúdos na escola, para que essa atribuição de sentidos, pelos alunos, motive-os a continuar com os estudos e com interesse. Então, verifiquei que devia iniciar com um diálogo para saber como queriam aprender e conduzir o planejamento das aulas nessa perspectiva. Anotei essa descoberta em meu caderno de notas.

Ao implementar esse primeiro plano de questionamento às crianças, perguntei à turma: "O que vocês querem aprender nas aulas de matemática? ". Percebi que os estudantes não estavam acostumados a manifestar seus interesses, pois a maioria dizia apenas: "Números", "Continhas"... Observei, então que eles não tinham grandes expectativas em relação à aprendizagem da matemática, pois uma criança disse: "a gente não gosta! ". As dificuldades apresentadas pelas crianças durante as aulas de matemática, em especial, referentes à solução de problemas matemáticos (eixo estruturante do currículo municipal) mostravam-se claramente ligadas à leitura, escrita e compreensão dos enunciados de problemas, o que suscitou a mim reflexões sobre a necessidade de trabalhar os conteúdos de forma interdisciplinar.

Nessa perspectiva, enquanto pesquisadoras, buscamos descrever e analisar os efeitos desse contato teórico e reflexão das ações das aulas que se seguiram. Após adotar a proposta da Pedagogia por Projetos, os alunos passaram a ter mais oportunidade de fala e expressão do corpo, sendo instigados a manifestar suas expectativas de aprendizagem, ficando perceptível que seus anseios e curiosidades correspondiam às propostas curriculares. Iniciamos, então, o projeto "Alimentação Saudável”, a partir de uma inquietação da própria turma referente à alimentação servida na escola.

O projeto "Alimentação Saudável” partiu da problematização levantada pelas crianças sobre os alimentos servidos na escola. Em roda de conversa, as crianças questionaram o porquê de determinados alimentos fazerem parte do cardápio, relatando não gostarem de macarrão com pouco molho e reivindicando alimentos como bolachas recheadas e salgadinhos de pacote.

Durante a conversa os estudantes solicitaram a presença da merendeira em sala de aula para que pudessem "reclamar" com ela, questionados por mim sobre a função da merendeira na escola, as crianças chegaram à conclusão que essa profissional apenas preparava os alimentos. À medida que se aprofundou a reflexão sobre o assunto, chegouse à conclusão de que há alguém responsável pela elaboração do cardápio, a nutricionista, e que determinados alimentos não colaboram para nossa qualidade de vida. 


\section{-Revista de Iniciação à Docência, v.6, n.2, 2021- \\ Publicação: dezembro, 2021 - ISSN 2525-4332}

Após esta conversa, as crianças se mostraram interessadas em conhecer a nutricionista e compreender todo o percurso dos alimentos até serem servidos na escola. Depois de muito concordarem e discordarem entre si, chegaram ao consenso sobre quais ações realizariam durante o projeto. Por fim, questiono às crianças "Vocês, então, gostariam de aprender matemática estudando a alimentação saudável? ". Responderam positivamente e mostraram-se animados, evidenciando que quando a proposta é significativa para o aluno e considera seu interesse, a aprendizagem torna-se prazerosa.

Acordou-se, então, que convidariam a nutricionista da escola para uma conversa. As crianças foram questionadas por mim sobre a maneira pela qual se faria o convite, logo responderam que deveriam falar com a diretora, então perguntei: "Como vocês falarão com a diretora? ". Uma das alunas sugeriu ir até a sala da diretora para resolver pessoalmente, outros disseram que poderiam ligar, até que, nos diálogos estabelecidos, um dos meninos levantou a sugestão de escreverem uma carta, algumas crianças não gostaram da ideia, porém chegaram ao consenso de que esta seria a melhor forma de solicitar a autorização da diretora para que pudessem realizar a conversa.

Restava ainda uma questão: de que maneira ocorreria a aprendizagem da Matemática no projeto "Alimentação Saudável”? Retomei a leitura dos capítulos 1 e 2 do livro de Jolibert et al. (1994a) e verifiquei que, ao decidir, escolher, regular, implementar, realizar no grupo, é preciso continuar a manter um diálogo constante com as crianças. A partir de então refleti com as crianças sobre o fato de encontrar a matemática em situações do cotidiano, como por exemplo na quantidade dos alimentos comprados. Logo começaram a surgir manifestações e observações diversas como o peso, tamanho, tempo de cultivo dos alimentos até que um dos estudantes contribuiu com a ideia de fazer um "bolo de forma" para estudar matemática com uma receita, o que foi prontamente aceito pelos demais.

Como os alunos acompanhavam o crescimento das beterrabas plantadas no projeto "Horta Educativa" (uma das ações do período integral dessa escola), sugeri que fizessem um bolo de beterraba, a ideia soou um pouco estranha para os alunos, porém a maioria dos estudantes ficou curiosa e decidiu aceitar. Em conversa sobre o assunto e sobre todas as ações que se realizariam durante o projeto, houve o confronto de ideias com respeito às opiniões e sugestões de todos, sempre havia algo a concordar e discordar e para chegarem a um propósito de ação comum para o grupo, passaram a desenvolver mais o diálogo ou votação, do que violência verbal e corporal, como no início do semestre. Muitas foram as vezes que tive de chamá-los para o compromisso que assumiram consigo mesmo e isso faz parte do processo de ensino das crianças para uma educação democrática. Em conjunto, foram elaborados os passos que levariam à consecução dos objetivos.

É relevante considerar que além dos objetivos pretendidos pelos estudantes na elaboração do projeto, o professor precisa ter claro os objetivos pedagógicos que 
nortearão suas ações pautados no interesse dos alunos. Assim, ao promover a discussão sobre o que os alunos almejavam e anotar posteriormente em meu caderno, busquei traçar os objetivos pedagógicos para o projeto, o que, de acordo com Jolibert et al. (2006), é um momento de relevante importância, pois o professor precisa saber e conhecer os objetivos que subjazem determinadas ações no magistério. Então, retomei o planejamento das novas ações a partir do que foi acordado com as crianças.

Entre os objetivos pedagógicos que surgiram no projeto, com base nas orientações curriculares do município (LIMEIRA, 2006) estão os de: reconhecer a alimentação saudável como um fator que contribui para a qualidade de vida do ser humano; elaborar, interpretar e resolver situações problemas; reconhecer a escrita como meio de comunicação; realizar diálogos argumentativos; respeitar regras de interação em uma conversa; interpretar e realizar a leitura de dados; construir listas, tabelas e gráficos e desenvolver as ideias relacionadas ao dobro e triplo.

Para as atividades e ações do projeto, fui elencando na lousa para planejarmos juntos, esse movimento que é, de acordo com Jolibert et al. (2006, p.34), "enriquecedor e surpreendente", e permite que o docente compartilhe com os estudantes "o sentido de sua atividade escolar", em uma relação de confiança e aceitação de que as contribuições da turma são valiosas para o processo de aprendizagem. Assim, com a participação dos estudantes, definimos que seria necessário a produção de textos para o andamento do projeto.

A medida que as ações se aproximavam, questionava os estudantes sobre qual seria a melhor maneira de encaminhá-las, diálogos estabeleciam-se até que chegavam ao consenso de que o texto colaboraria para a consecução das atividades, como pode ser observado na conversa transcrita a seguir:

Professora: Bem, sabemos que vocês desejam conversar com a nutricionista da escola, correto? Essa conversa pode ocorrer de qualquer maneira? Vocês acreditam que podemos chegar ao local $e$ falarmos qualquer coisa?

Aluno 1: Na verdade não, professora! Se a gente não ficar organizado, vai virar bagunça, todo mundo vai falar ao mesmo tempo e ninguém vai entender nada.

Professora: Então, como vocês pensam que poderia ser essa organização?

Aluno 2: Não é uma entrevista? Então, sabe, a gente tem que fazer igual no jornal da televisão, a gente tem que falar certinho.

Professora: Você quer dizer que precisamos usar uma linguagem formal?

Aluno 3: Isso, mas a gente tem que perguntar e também falar o que a gente quer.

Professora: Para isso precisamos nos preparar, correto?

Aluno 2: Sim, professora, vamos escrever no papel o que a gente quer perguntar e falar para ela.

Professora: Podemos então produzir um cartaz com o roteiro da entrevista e sugestões. Vocês 
concordam?

\section{Alunos: Sim, professora, vai ficar mais fácil para gente.}

Destacamos que, dentre os textos produzidos e necessários para realização do projeto, houve: cartas, convites, cartazes, roteiro de entrevista, receita e enunciados de problemas matemáticos, mostrando o quanto a alfabetização da língua e a matemática estão interligadas. A cada texto produzido coletivamente, conversava com os alunos sobre sua estrutura e elementos necessários para composição, bem como disponibilizava para a turma o estilo de composição desses textos.

A seguir descreveremos o andamento do projeto e suas implicações para as minhas reflexões pessoais como professora e o movimento que este causou no processo de ensino.

\section{O desenvolvimento do projeto e suas decorrências}

Com o projeto definido, iniciamos as ações combinadas, articuladas com a participação da professora de Língua Portuguesa, que realizou a escrita coletiva de uma carta para a direção da escola, solicitando a visita da nutricionista para uma conversa sobre a merenda, bem como um convite direcionado à nutricionista. Cabe ressaltar que houve uma conversa prévia com a direção da escola, sobre os objetivos e ações que seriam realizados durante o projeto. A diretora concordou com a solicitação enviada pelos alunos e respondeu com uma carta, o que causou expectativas em relação à entrevista.

No dia 31 de outubro, durante a entrevista, os estudantes tiveram a oportunidade de esclarecer dúvidas, fazer sugestões sobre a merenda, desenvolvendo, também, a oralidade, além da leitura e escrita. Nesse momento estabeleceu-se um diálogo argumentativo, em que os discentes buscaram usar vocabulário coerente, respeitando as regras de interação entre as falas e sustentando o ponto de vista colocado por eles durante a problematização, como por exemplo, a sugestão para que houvesse sobremesa após o almoço.

Dessa forma, as dúvidas levantadas com referência à merenda foram esclarecidas e os estudantes puderam compreender o porquê de algumas decisões serem tomadas, ou não, no que se refere à alimentação na escola, especificamente, como a questão da gelatina, que não é servida pela falta de recursos para mantê-la refrigerada, visto que a Unidade Escolar divide o espaço da cozinha com um Centro de Educação Infantil. Algumas crianças mostraram-se frustradas, então conversamos sobre aquilo que é possível no meio escolar e o que pode se adequar.

Após a entrevista com a nutricionista, colocamos em prática a ideia de fazer um bolo com as beterrabas colhidas na horta. Antes da colheita, foi estudada a ficha técnica da beterraba, comparando os dados com os de outra turma de $2^{\circ}$ ano que havia plantado 


\section{-Revista de Iniciação à Docência, v.6, n.2, 2021- \\ Publicação: dezembro, 2021 - ISSN 2525-4332}

rabanetes. Foi feita a estimativa de quando seria a colheita que em decorrência de condições climáticas foi prorrogada por mais duas semanas. Para essa atividade, o uso do calendário foi imprescindível, tanto na compreensão deste como instrumento de medida do tempo e sua utilização social, bem como para o entendimento de sequências numéricas e regularidades do sistema de numeração decimal, visto que foram contados os dias estimados para colheita, observando os números em sua sequência.

O calendário propiciou o trabalho com situações problemas envolvendo a subtração e a ideia de completar quantidades, pois cotidianamente, questionava a turma sobre quantos dias faltavam para a colheita. Com a colheita da beterraba realizada, estudamos previamente a receita do bolo, observando os instrumentos de medidas convencionais que seriam utilizados e suas respectivas unidades de medidas (Quilograma e Litro), bem como a quantidade de ingredientes. Refletimos sobre instrumentos de medidas não convencionais utilizados pelas cozinheiras como colher, xícara e copos.

Questionei os alunos sobre a quantia de bolo que seria feita, visto que duas turmas participariam desta atividade, "será que apenas uma receita de bolo é o suficiente para todos experimentarem"? A resposta negativa por parte das crianças levou a reflexões sobre o dobro e triplo, o que posteriormente foi vivenciado na prática durante a execução da receita e sistematizado em atividades durante as aulas.

Figura 1: atividade envolvendo o dobro da receita do bolo de beterraba.

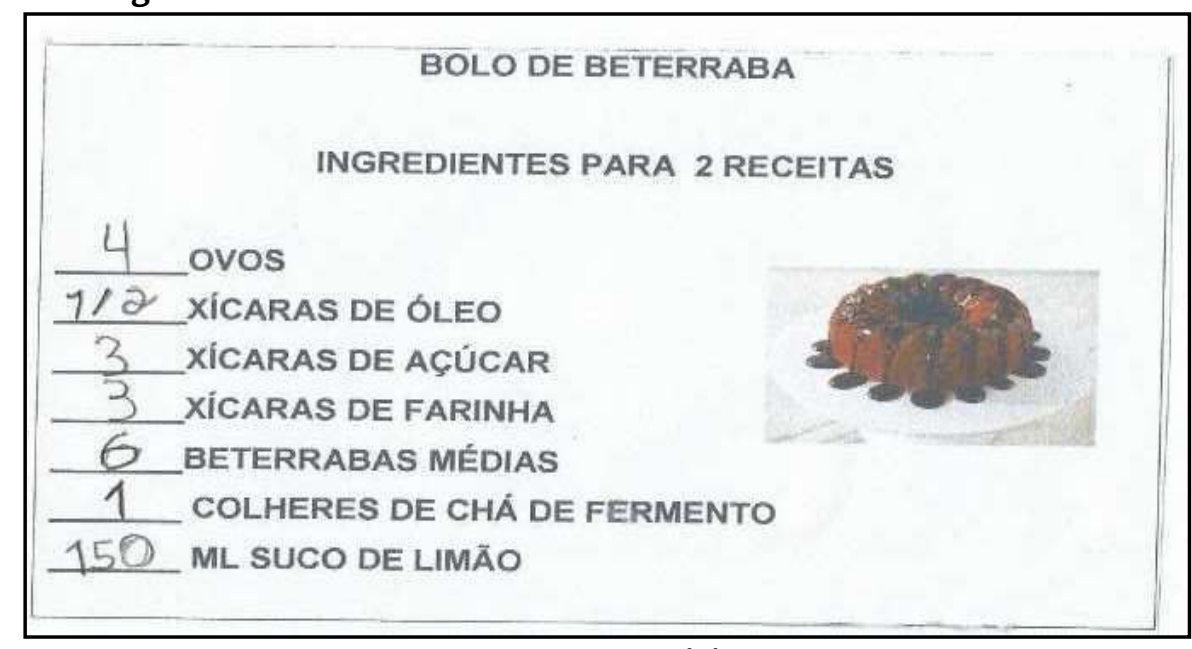

Fonte: Acervo pessoal das autoras.

A cada passo da receita, analisamos a quantidade e medida dos ingredientes como pode ser observado nas figuras $2 \mathrm{e} 3$. 
Figura 2: Preparo do bolo de beterraba.

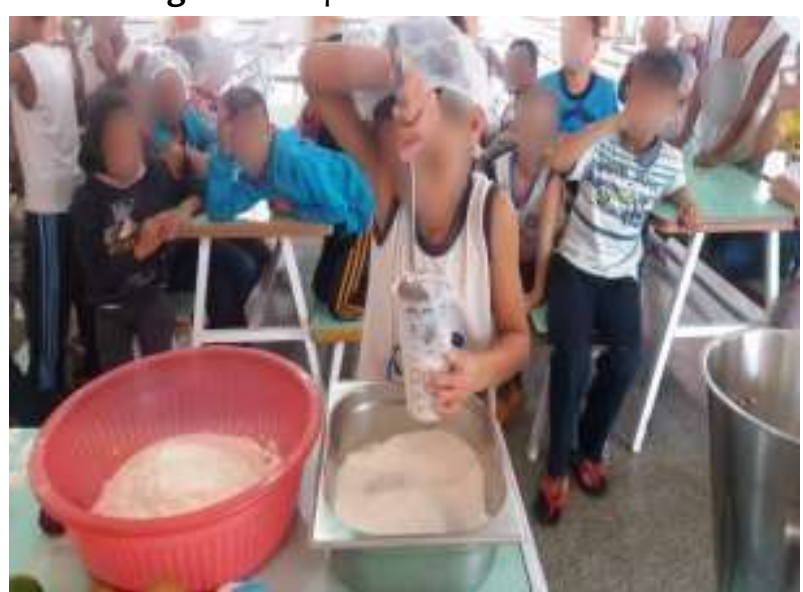

Fonte: Acervo pessoal das autoras.
Figura 3: Preparo do bolo de beterraba.

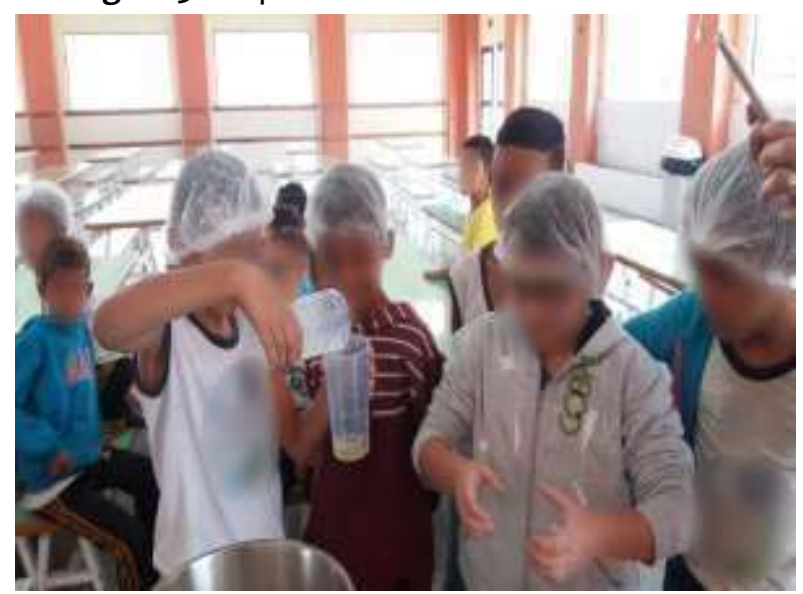

Fonte: Acervo pessoal das autoras.

Após esse momento, busquei pesquisar algo sobre a importância da aprendizagem da educação matemática e registrei em meu caderno de notas a ideia de que a educação matemática pressupõe a criação de situações que promovam o desenvolvimento da aprendizagem, estimulando descobertas e potencializando a capacidade dos alunos (RAMOS, 2009) essa reflexão relaciona-se bem com esse momento do percurso do Projeto da turma.

Assim, em cada ação realizada no projeto, houve a construção de problemas matemáticos, tanto por mim, quanto pelos próprios estudantes que tiveram a oportunidade de elaborar, realizar, vivenciar e interpretar essas situações por meio de diferentes estratégias até chegar as técnicas operatórias que compõem a grade curricular.

De acordo com o currículo da Rede Municipal de Ensino (LIMEIRA, 2016), é importante que os alunos identifiquem os conteúdos matemáticos aprendidos na escola em acontecimentos do seu cotidiano e encontrem soluções para os problemas que se fazem presentes em seu dia a dia. Portanto, como orienta o documento, os conteúdos matemáticos precisam estar relacionados a situações-problemas a fim de que não sejam apenas atividades repetitivas. A BNCC (BRASIL, 2017, p.59) aponta que "a relação com múltiplas linguagens, incluindo os usos sociais da escrita e da matemática, permite a participação no mundo letrado e a construção de novas aprendizagens, na escola e para além dela".

No decorrer do projeto, observei que ao fazer uso da linguagem em situações reais de aprendizagem, como a leitura e produção de textos para atender as propostas elaboradas no projeto, os estudantes passaram a compreender melhor os enunciados das situações-problemas buscando com autonomia solucioná-las.

Logo, percebi que as ações do projeto, corresponderam às orientações do 
currículo e propiciaram aos alunos a oportunidade para vivenciar a matemática no cotidiano e à mim de exercer uma prática significativa, o que pode ser observado em anotação no meu caderno de notas: "ao trabalhar com a Pedagogia por Projetos senti a materialização de uma proposta de ensino de fato ativa, percebi que não é preciso estar no controle o tempo todo para que a aprendizagem ocorra, pude experimentar o que significa ser um professor mediador, o que muito me confundia no período de formação, compreendi que a partir do momento que o aluno atribui significado ao estar na escola, não se faz necessário uma postura autoritária por parte do professor para que o estudante esteja engajado no objeto de estudo. A Pedagogia por Projetos me movimenta enquanto profissional, me desestabilizando frequentemente e me permitindo reconstruir a prática pedagógica".

Mediante o entusiasmo dos alunos com o retorno positivo das propostas pensadas por eles no início do projeto, desenvolvemos outras ações relacionadas, como a pesquisa referente aos alimentos naturais e industrializados utilizados na receita do bolo. $\mathrm{Em}$ um primeiro momento, foram identificados os alimentos naturais e os industrializados, contidos na receita, registrando-os na lousa. Depois, foi produzido um cartaz contendo apenas os ingredientes naturais e realizada uma votação na qual cada criança deveria escolher seu alimento preferido. Os dados obtidos foram organizados em tabela simples. Esta atividade envolveu reflexões sobre a estrutura da tabela (linhas e colunas), bem como os dados necessários para sua composição como título e fonte. Em seguida, com os dados coletados e analisados foi elaborado um gráfico de colunas.

Figura 4: Exemplo de atividade envolvendo tabela simples.

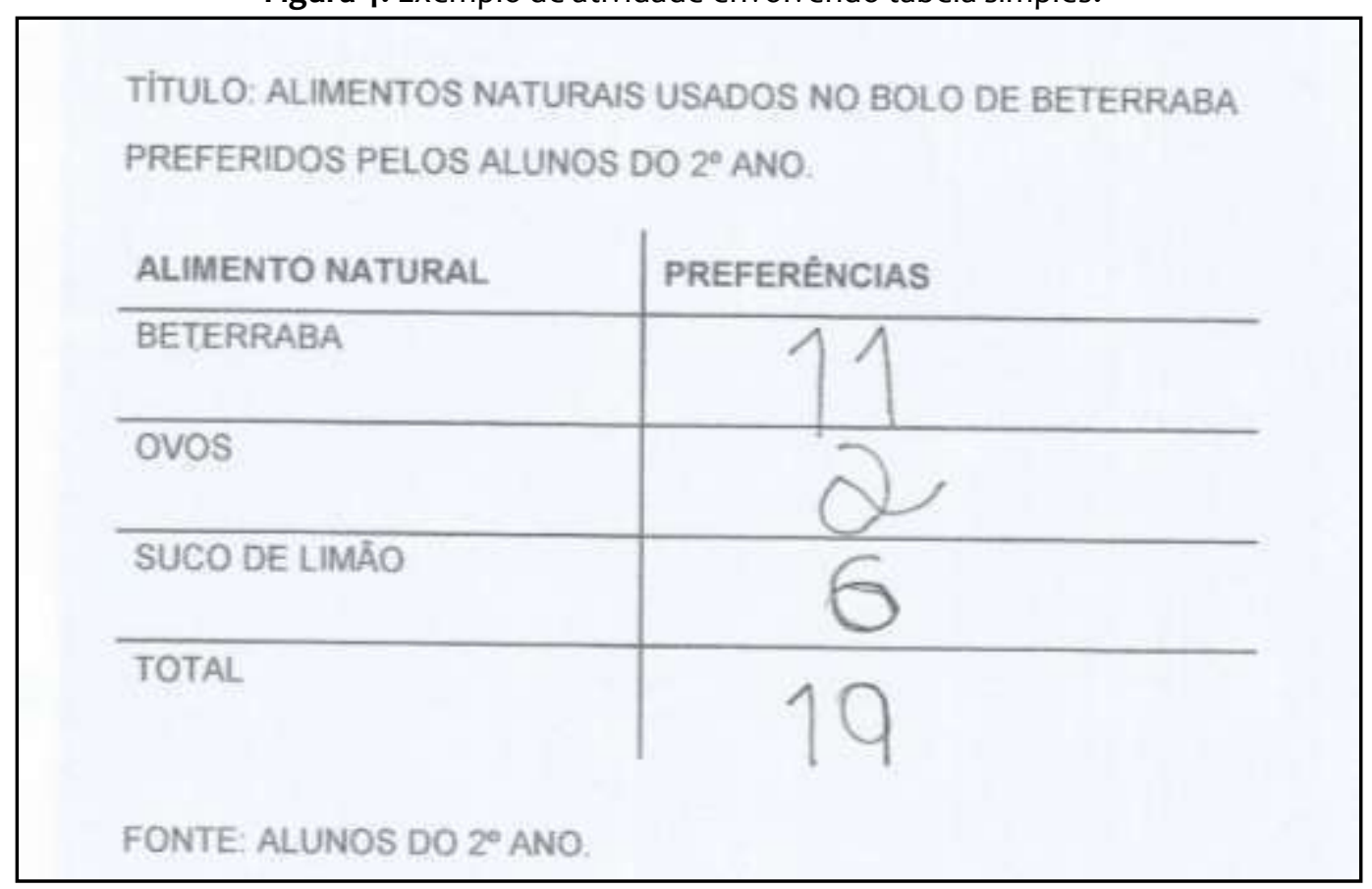

Fonte: Acervo pessoal das autoras. 
-Revista de Iniciação à Docência, v.6, n.2, 2021-

Publicação: dezembro, 2021 - ISSN 2525-4332

Figura 5: Exemplo de atividade envolvendo gráfico de colunas.

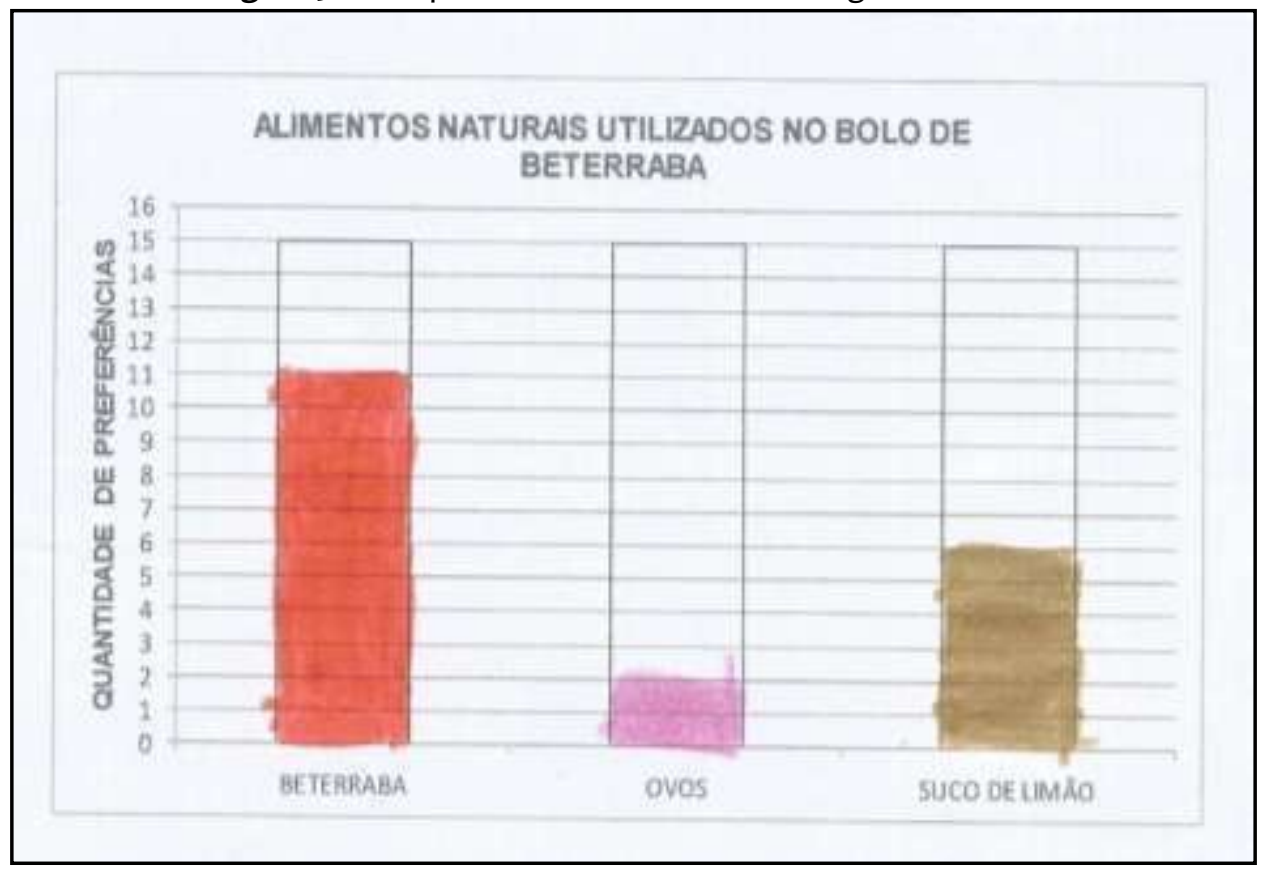

Fonte: Acervo pessoal das autoras.

Cabe destacar que depois de realizarem esta atividade, fiz uma avaliação de minhas ações e da turma. Retomei a leitura do início do Capítulo 1 (JOLIBERT; SRAÏKI, 2008, p.23) e verifiquei com as autoras que, “o que está em jogo são as situações cotidianas em que a escola, como instituição, e o grupo-classe representam esse ambiente de vida e de trabalho para as crianças (...) [isso] implica valores, representações, concepções, escolhas teóricas e procedimentos pedagógicos"”. Anotei o que aprendi e refleti sobre o planejamento do final do projeto elaborado junto às crianças.

\section{Finalização do projeto e reflexão teórico-prática}

Para o encerramento do projeto os estudantes sugeriram um piquenique. Conversamos então com a coordenação pedagógica que buscou autorização e recursos. Enviamos um convite à nutricionista da escola para participar do piquenique e ela, prontamente, respondeu por meio de uma carta. O piquenique foi realizado no Horto Florestal da cidade, onde os alunos puderam compartilhar suas experiências e alimentos, expressando o quão proveitoso foi o projeto para eles. Também foi produzido coletivamente um relatório final, a fim de que pudesse ser levado para casa junto à receita do bolo de beterraba, atendendo à solicitação dos próprios alunos.

Consultei na literatura científica que a vida cooperativa permite que a criança "viva seus processos autônomos de aprendizado e se insira num grupo e num meio considerados como estrutura que estimula, que exige, que valoriza, que provoca contradições e conflitos e que cria responsabilidades" (JOLIBERT et al., 1994a, p.20).

Em consequência do trabalho realizado sob a perspectiva da Pedagogia por 


\section{-Revista de Iniciação à Docência, v.6, n.2, 2021- \\ Publicação: dezembro, 2021 - ISSN 2525-4332}

Projetos, o ano letivo foi finalizado com as condutas dos educandos significativamente transformadas tanto no que se refere às questões de convivência na escola. Quanto ao aprendizado, mesmo que alguns dos estudantes não atingiram o esperado para o ano de escolaridade, as condutas dos alunos manifestaram compreensão de que a escola é um espaço democrático no qual eles podem decidir e atuar. Foi um trabalho construído no coletivo e com muito diálogo, quando alguma discussão se iniciava, eram sempre alertados que a conversa é um recurso da democracia e precisa ser utilizada para o bem comum.

Dessa forma, percebi que, ao elegermos em conjunto as atividades e ações que seriam realizadas durante o projeto, os estudantes tiveram a oportunidade de tomada de decisão. A matemática que antes era, segundo as crianças, "um pesadelo”, passou a ser a área do conhecimento favorita de muitos, pois, ao serem protagonistas nas ações, puderam perceber que as questões que envolvem a matemática vão além de números e operações. Como pode ser observado na fala transcrita de um dos estudantes: "Nossa professora! Eu não sabia que estudar matemática podia ser tão legal. Eu odiava matemática, ficar só fazendo aquelas contas chatas, agora matemática vai ser para sempre a minha favorita".

Quanto ao comportamento da turma, passou a apresentar-se tolerante. Como aqui mencionei, as crianças valorizaram mais o diálogo e a interação respeitosa entre seus pares, sendo capazes de respeitar as regras de convivência tanto em sala de aula, como em outros espaços escolares, com os alunos reconhecendo-se como sujeitos com direitos e deveres e, especialmente, pelo poder de decisão.

Esse fato pode ser observado em um dos diálogos entre os estudantes quanto à conquista do piquenique e a decisão em convidar a nutricionista para participar: "A ideia do piquenique foi nossa, a gente que decidiu fazer isso, viu como saber ler e escrever é importante! A gente conquista muitas coisas", reproduzindo uma fala minha do início do Projeto e demonstrando que compreenderam a função social da escrita; outra criança: "Quem decidiu convidar a nutricionista foi a gente, a gente que escolheu fazer isso porque ela foi muito legal dando a entrevista, a professora só entregou o convite. Isso foi por causa do nosso projeto".

Importante destacar que estes diálogos aconteceram no processo da "atividade de metacognição" (JOLIBERT et al., 2006, p.16) que consiste no momento, no coletivo, de parar e refletir sobre a realização das atividades, o processo de ensino e aprendizagem e o que foi aprendido até ali, para perceberem e saberem argumentar sobre os caminhos percorridos e dos conhecimentos adquiridos.

Portanto, concluí que a Pedagogia por Projetos, aliada ao trabalho pedagógico interdisciplinar, se constitui em uma ferramenta significativa para o êxito do educando como sujeito do processo de ensino e de aprendizagem ao ser considerado o objeto de interesse do discente, propicia a construção de novos saberes e a consolidação das 


\section{-Revista de Iniciação à Docência, v.6, n.2, 2021- \\ Publicação: dezembro, 2021 - ISSN 2525-4332}

habilidades adquiridas por ele e também a mim enquanto profissional docente em formação.

Considerando que a ação docente é permeada por diferentes desafios, cabe ressaltar que nesse artigo focalizamos o trabalho realizado durante o projeto “Alimentação Saudável" e que o tempo de duração do projeto, como mencionado foi de apenas três meses, não havendo possibilidade de nivelar os conhecimentos da turma segundo os critérios estabelecidos pela rede de ensino, no entanto, cada pequena evolução das crianças em particular me possibilitou compreender que a aprendizagem vai além de absorver conteúdos e o ensino não é transmissão de conhecimentos e sim construção, "[...] ensinar não é transferir conhecimento, mas criar as possibilidades para a sua produção ou a sua construção" (FREIRE, 2002, p.12).

\section{Considerações Finais}

Este artigo, ao discorrer e analisar sobre as ações pedagógicas de uma das autoras enquanto professora pesquisadora iniciante de carreira e a relação com o saber teórico, numa concepção de ensino da Pedagogia Ativa - Pedagogia por Projetos, buscou alinhavar o caminho delineado pelas ações práticas com os conhecimentos teóricos que fizeram sentido na aplicabilidade e na reflexão-ação do percurso, a fim de aprimorar a formação como professora alfabetizadora.

Foi possível constatar que, ao buscar as contribuições da Pedagogia por Projetos, encontramos nessa proposta a possibilidade de relacionar a teoria com a prática de um modo significativo não só para o docente, mas também para os estudantes, motivandoos ao desempenho das ações. Ao refletir sobre o que fazem e dizem, ao registrar esse processo e descobertas práticas e teóricas, reconhecemos a importância desses atos para o (re)planejamento das aulas, em busca de melhorar a aprendizagem de cada aluno.

Nessa perspectiva, verificamos nas anotações reflexivas e nas avaliações durante o processo, que os alunos adquiriam conhecimentos interdisciplinares, cada um a seu modo e com suas dificuldades, e que também se envolveram no seu próprio processo de aprendizagem, reconhecendo a importância da leitura e da escrita para a aquisição de seus objetivos.

Assim, esta pesquisa confirma o pressuposto, levantado inicialmente, de que a aprendizagem do ensino pelo professor no processo de sua ação prática possibilita assimilações mais eficazes sobre sua formação e sobre os seus saberes no exercício de sua profissão (TARDIF, 2002), e quando este professor busca subsídios teóricos para refletir sua prática pedagógica pode compreender também o processo de aprendizagem do aluno de um modo mais fundamentado.

Em suma, na relação com o saber docente e conceitual, muitos são os caminhos para a aquisição dos conhecimentos de uma profissão e todos são trabalhosos, porém os 
mais assertivos, na concepção desta pesquisa, são aqueles que se associam aos projetos de vida das pessoas, propiciam interações com seus pares e aliam-se a objetos de estudo que educam para a autonomia dos atos e dos pensamentos numa aproximação com uma vida cooperativa na escola e para além dela.

\section{Referências}

BRASIL, Constituição (1988). Constituição da República Federativa do Brasil. Brasília, DF: Senado Federal. Disponível em:

http://www.planalto.gov.br/ccivil_03/constituicao/constituicao.htm. Acesso em: 10 mar. 2020.

BRASIL, Ministério de Educação e Cultura. LDB - Lei n 9394/96, de 20 de dezembro de 1996. Estabelece as diretrizes e bases da Educação Nacional. Brasília: MEC, 1996. Disponível em: http://www.planalto.gov.br/ccivil_03/leis/l9394.htm. Acesso em: 10 abr. 2020.

BRASIL. Ministério da Educação. Secretaria da Educação Básica. Base Nacional Comum Curricular. Brasília: MEC, 2017. Disponível em:

http://basenacionalcomum.mec.gov.br/images/BNCC_El_EF_110518_versaofinal_site.pdf. Acesso em: 10 mar. 2020.

LIMEIRA (SP). Secretaria Municipal de Educação. Diretoria Pedagógica. Resolução SME $\mathbf{n}^{\circ}$ 11/2016, de 29 de dezembro de 2016. Dispõe dobre o Currículo da Rede Municipal de Educação de Limeira. Limeira: SME, 2016.

FREIRE, Paulo. Pedagogia da Autonomia: saberes necessários à prática educativa. 25ed. São Paulo: Paz e Terra, 2002.

JOLIBERT, Josette et al. Formando Crianças Leitoras. Porto Alegre: Artmed, 1994a. Tradução: Bruno Charles Magne.

JOLIBERT, Josette et al. Formando Crianças Produtoras de Texto. Porto Alegre: Artmed, 1994b.Tradução: Walkiria M. F. Settineri eBruno Charles Magne.

JOLIBERT, Josette et al. Além dos Muros da Escola: a escrita como ponte entre alunos e comunidade. Porto Alegre: Artmed, 2006. Tradução: Ana Maria Neto Machado.

JOLIBERT, Josette et al. Transformando a formação docente: uma proposta didática em pesquisa-ação. Porto Alegre: Artmed, 2007.Tradução:Valério Campos.

JOLIBERT, Josette; SRAÏKI, Christine. Caminhos para aprender a ler e escrever.São Paulo: Contexto, 2008.Tradução:Ângela Xavier de Brito.

LIMA, Maria Socorro Lima; BRAGA, Maria Margarete Sampaio de Carvalho. Relação ensino-aprendizagem da docência: traços da pedagogia de Paulo Freire no ensino superior. Educar em Revista, Curitiba, v. 32, n. 61, p. 71-88, jul./set. 2016. Disponível em: https://www.scielo.br/j/er/a/mFvDbRfC5LVsH8fzyjgCcHc/?format=pdf\&lang=pt. Acesso em: 18 jan. 2020.

MICOTTI, Maria Cecília de Oliveira (org.). Alfabetização: a produção de saberes. Rio Claro: UNESP - Instituto de Biociências, 2003.

MICOTTI, Maria Cecília de Oliveira (org.). Leitura e Escrita: como aprender com êxito por 
meio da pedagogia por projetos. São Paulo: Contexto, 2009.

MICOTTI, Maria Cecília de Oliveira. Alfabetização: propostas e práticas pedagógicas. São Paulo: Contexto, 2017.

NÓVOA, António. Os professores e sua formação. Lisboa: Dom Quixote, 1992.

NOVOA, António. Firmar a posição como professor, afirmar a profissão docente.

Cadernos de Pesquisa, v.47, n. 166, p. 1106-1133,São Paulo, out./dez. 2017. Disponível em: https://www.scielo.br/j/cp/a/WYkPDBFzMzrvnbsbYjmvCbd/?format=pdf\&lang=pt. Acesso em: 28 fev. 2020.

ORTIZ, Heloísa Martins e. O professor reflexivo: (re) construindo o "ser" professor. In. IV Congresso de Educação do Movimento Humanidade Nova - Educação a fraternidade: um caminho possível? Vargem Grande Paulista, Movimento Humanidade Nova - Sala Temática: O professor reflexivo, p. 1-10, 2003.

PIMENTA, Selma Garrido. Pesquisa-ação crítico-colaborativa: construindo seu significado a partir de experiências com a formação docente. Educação e Pesquisa, São Paulo, v. 31 n.3, p. 521-539.set./dez. 2005.Disponível em: //www.scielo.br/pdf/ep/v31n3/a13v31n3.pdf Acesso em: 05 mar. 2020.

RAMOS, Luzia Faraco. Conversa sobre Números, Ações e Operações: uma proposta criativa para o ensino da matemática nos primeiros anos. São Paulo: Ática, 2009.

SANTOS, Sydione. Aprendizagem da Docência e Formação Inicial: concepções e propostas. In. Anais, XII Congresso Nacional de Educação - EDUCERE, p. 18.119 - 18.135, Curitiba: PUC-PR, 2015. Disponível em:

https://educere.bruc.com.br/arquivo/pdf2015/16228_7590.pdf Acesso em: 20 mar. 2020.

SCHÖN, Donald. Formar professores como profissionais reflexivos. In: NÓVOA, António (coord.). Os professores e sua formação. Lisboa: Dom Quixote, 1992.Tradução: Graça Cunha, Cândida Hespanha, Conceição Aafonso e José António Sousa Tavares.

SHÖN, Donald. Educando o profissional reflexivo: um novo design para o ensino e a aprendizagem. Porto Alegre: Artmed, 2000.Tradução: Roberto Cataldo Costa.

SMYTH, J. Teachers' Work and the Politics of Reflexion. American Educational Research Journal, 1992.

TARDIF, Maurice. Saberes Docentes e Formação Profissional. Petrópolis: Vozes, 2002.

TARDIF, Maurice. A profissionalização do ensino passados trinta anos: dois passos para a frente, três para trás. Educação \& Sociedade, Campinas, v. 34, n. 123, p. 551-571, abr./jun. 2013. Disponível em: https://www.scielo.br/pdf/es/v34n123/13.pdf. Acesso em: 03 jun. 2020.

TRIPP, David. Pesquisa-ação: uma introdução metodológica. Educação e Pesquisa, São Paulo, v. 31, n.3, p. 443-466, set./dez. 2005. Disponível em: https://www. scielo.br/pdf/ep/v31n3/aogv31n3.pdf. Acesso em: 23 ag. 2020. 